\title{
Determining The Factors Affecting Demand For Branded Beef: Applying A Logit Model To 2004 Neilson Home-Scan Data
}

Steve Martinez, (E-mail: martinez@usda.ers.gov), USDA-ERS

Roger Hanagriff, (E-mail: agr_rdh@shsu.edu ), Sam Houston State University

Michael Lau, (E-mail: michaellau@shsu.edu), Sam Houston State University

Michael Harris, (E-mail: jharris@ers.usda.gov), USDA-ERS

\begin{abstract}
This paper finds that branded fresh beef expenditures increased from 20.8 percent in 1998 to 28.6 percent in 2004 for all fresh beef expenditures. In addition, geographic location, household income, household race, and household size were found to affect the likelihood of branded fresh beef purchases in 2004.
\end{abstract}

Keywords: Branded beef, Demographics, Demand, Panel Data, Logit

\section{INTRODUCTION}

\begin{abstract}
$\mathrm{n}$ the past 20 years, the beef industry has experienced significant changes with beef at the retail counter. With health and convenience being the initial driving factors, more recent changes have occurred due to palatability preferences and safety concerns of the consumer. These changes have spurred new marketing programs, which include product differentiation and changes in production. Consumers today purchase many branded products because of the perceived value and quality they receive.
\end{abstract}

These changes in consumer preferences and lifestyles have altered the marketing of products and services. In today's agriculture world, "value added" is a key term used by many individuals to describe the current marketing state of products. Value added is a very broad term that encompasses a wide range of attributes such as packaging, pre-cooked, serving size and any enhancement a company gives a product or service before offering it to the consumer. This term is often synonymous with the term "branded," and if these brands offer a perceived extra value, then that value becomes the major motivation for a consumer to buy or use the product.

Because of this, marketplace pressures are changing the emphasis of stakeholders throughout the beef supply chain. Demand from end-use customers is pulling product through retail as retailers demand increasingly differentiated products. The packer is no longer the primary driver of supply, price, and product form within the chain. Consolidation of food retailers and efforts to differentiate themselves from nontraditional food retail outlets, such as super centers, warehouse clubs, and specialty stores, are giving retailers greater influence over pricing and product attributes (Martinez, 2007). Demands from food retailers include source and age verification, and products from other specialty programs that offer opportunities for product differentiation.

Beef branding programs offer a means for satisfying consumer demand for high quality, differentiated beef products. Because of the emphasis on value, interest in brand marketing and recognition has increased greatly. This is clearly evident where brands such as Certified Angus Beef, Omaha Steaks, and Nolan Ryan Beef have evolved through distinct desirable characteristics of their beef products. Consumers search out these specific branded beef

\footnotetext{
${ }^{1}$ Selected Paper prepared for presentation at Clute Research Institute Research Conference Mazatlan, Mexico, March 26-29,
} 2007. Views expressed are those of the authors and not necessarily those of the U.S. Department of Agriculture. 
products as they expect a higher quality and are willing to pay a premium for it. Companies are using their brand to increase the value of their product.

However, many of the most important quality attributes to consumers of beef such as flavor, tenderness, nutrition, and safety are not apparent to consumers until the product is consumed. A number of studies have shown that consumers are willing to pay a premium for more tender beef. Lusk et al (2001), for instance, found that over half the participants in one study would be willing to pay more for higher quality beef.

Emerging consumer concerns such as the humane treatment of farm animals and environmentally friendly production practices are also impossible to detect even after consumption. Many consumers, for instance, are concerned about the potential adverse health effects of growth hormones given to livestock. Loureiro and Umberger (2004) found that consumers were willing to pay significant premiums for assurance that beef has been food safety inspected and that the product can be traced back to the farm of origin.

Because most attributes cannot be detected till after consumption, this can lead to market failure that may prevent consumers and producers from engaging in what would otherwise be a mutually beneficial transaction. The use of brand names and firm reputation to assure food product performance and safety is one possible private solution to this market failure problem.

In general there are 3 types of branded beef (Washington State Beef Commission, 2006), which include breed-specific, company-specific and other store-branded products. Breed-specific branded beef selects beef from a specific breed. For example, Certified Hereford Beef targets Hereford cattle. Company-specific branded beef selects beef from all breeds but includes other criteria, such as no antibiotics or hormones, source verified, and grass-fed. Examples include Laura's Lean Beef and Maverick Ranch. Store-branded beef is branded by a grocery store company, such as Food Lion's Butcher's Brand Premium Beef. Food Lion's premium beef, for example, is sourced from Midwestern producers that comply with the company's standards for beef quality, including marbling and aging.

Previous studies have found a branded beef label to be less important than other attributes, and that the likelihood of purchasing branded products varies by the consumer demographic characteristics. One mail survey found that a brand label on a steak was the least important attribute among the six attributes examined, while color was identified as the most important (Lusk, 2001). This suggests that branding is of little importance, and attempts to differentiate may be unsuccessful. Another study using consumer panel data across 25 food, beverage, and nonfood categories found that baby boomers are more likely to purchase branded products than younger shoppers (Business Wire, 2006).

In their study using household panel data from the National Panel Diary Group Company, Ward and Ferrara (2005) found an increase in average brand preferences for beef, from 13 percent in 1992 to 22 percent in 2000. Demographics, while statistically significant, had relatively minor effects on brand preferences. On the other hand, type of store (for example, supercenters, supermarkets) and location within store (for example, fresh meat case, freezer section, deli and food bar) were found to have substantial effects on the likelihood of buying by brand.

The major objective of this research is to evaluate the growth of branded beef sales and to describe the characteristics of consumers purchasing branded beef products. The questions to answer concern what factors affect the purchase of branded beef products and what are the implications for future growth of branded beef product sales? We first examine current trends in branded beef purchases. Next, we conduct a more in depth analysis of important factors affecting the likelihood of branded beef purchases. Finally, we identify household characteristics most likely to purchase branded beef. 


\section{BRANDED FRESH BEEF CONSUMPTION PATTERNS}

The data to complete these objectives is Nielsen Homescan household panel data from 1998 to 2004 and examine branded fresh beef consumption in 7 major retail channels (i.e., supercenters, grocery stores, warehouse clubs, drugstores, convenience stores, mass merchandisers, and other). Nielsen's Homescan panel data provides transaction prices for food product purchases, quantities, information on the attributes of branded and private label products, and information on household demographics, such as age race, and income. Households in the sample record purchases they make using a scanner located at their home. For products without barcodes, information is recorded manually.

The data allows researchers to conduct in depth analysis of heterogeneous preferences toward beef purchases of U.S. households. This contrasts with existing government surveys, such BLS Consumer Expenditure Survey, which is a primary source for aggregate food-at-home and food-away-from home expenditures. Aggregate data are less revealing when aggregate observations are confounded by economic and demographic shifts. Although aggregate data have a significant place in applied work, it may be advantageous to study micro data, which provide richer opportunities for analyzing consumer behavior. The use of A.C. Nielsen data allows a unique opportunity to study branded beef.

Fresh beef in the AC Nielsen data is contained in three product modules, which is a three or four-digit code used to identify product categories. The data include random weight and fixed-weight items for various cuts, including ground beef, beef for stew, fillet, tenderloin, steak, roast, and others. ${ }^{2}$ Product identification also includes a label as either a type of branded or non-branded beef. Most random weight beef is classified as either "no brand" or "all other brands." The fresh beef product grouping, which includes the fixed-weight items, contains several brand descriptions.

These include the actual brand name (for example, Laura's Lean Beef), "CTL BR," which are private label products (for example, Safeway's Rancher's Reserve brand), a processor name followed by "no brand label" (for example, Tyson Fresh Meats-NBL), and no brand label---"no company listed" (for example, NBL-no company listed). To delineate branded from non-branded beef, we attempt to match the definition of branded beef described above with the brand descriptors in the AC Nielsen data set (Table 1). All fresh beef with a brand name and the "CTL BR" items are considered to be branded.

\begin{tabular}{|c|c|c|c|}
\hline \multicolumn{5}{|c|}{ Table 1. Branded fresh beef classifications using AC Nielsen brand descriptions } \\
\hline $\begin{array}{c}\text { Product } \\
\text { module code }\end{array}$ & $\begin{array}{c}\text { Product module } \\
\text { description }\end{array}$ & Brand description & Branded? \\
\hline 3561 & Fresh beef & $\begin{array}{c}\text { Brand name } \\
\text { (e.g., Laura's Lean Beef, Excel) }\end{array}$ & Yes: company-specific \\
\hline 3561 & Fresh beef & CTL BR & Yes: store-branded \\
\hline 3561 & Fresh beef & NBL-no company listed & No \\
\hline 3561 & Fresh beef & Supplier name listed (e.g., Tyson Fresh Meats-NBL) & No \\
\hline 706 and 737 & Random weight beef & No brand & No \\
\hline 706 and 737 & Random weight beef & All other brands (e.g., store name, such as Giant) & Yes: store-branded \\
\hline
\end{tabular}

We first use the AC Nielsen data to provide summary information on U.S. branded beef expenditures. In 2002, AC Nielsen collected data from 91,000 households, up from 55,000 in 1999 (Harris and Blisard). The sample was selected based on demographic and geographic targets. To aggregate to the U.S. level, projection factors contained in the data set are used to produce demographic weighting and aggregation to the U.S. level. The projection factors weight each household according to its representation in the U.S. population based on U.S. Census. Aggregation to the U.S. level is based on household population projections.

${ }^{2}$ Random-weight items are products sold that vary in weight. On the other hand, fixed-weight items are sold in standard-sized packages with fixed weights. 
We estimate U.S. consumers spent $\$ 3.6$ billion on branded beef in 2004, which was 28.6 percent of fresh beef purchases (Table 2). The percent spent on branded beef has increased steadily since the late 1990s, up from 20.8 percent in 1998. The percent of branded product varied depending on product form (Table 3). In 2004, 32.9 percent of ground beef was estimated to be branded, compared to 25.8 percent of the whole muscle cuts. This is up from 19.4 percent and 21.6 percent in 1998 , respectively.

\begin{tabular}{|c|c|c|c|c|c|c|c|}
\hline \multicolumn{7}{|c|}{ Table 2. Branded beef expenditures as a percent of total fresh beef sales, 1998-2004 } \\
\hline & 1998 & 1999 & 2000 & 2001 & 2002 & 2003 & 2004 \\
\hline $\begin{array}{c}\text { Total fresh } \\
\text { beef }(\$ 1,000)\end{array}$ & $11,151,599$ & $11,518,339$ & $11,652,169$ & $11,806,669$ & $11,561,300$ & $11,377,205$ & $12,465,9$ \\
\hline $\begin{array}{c}\text { Branded beef } \\
(\$ 1,000)\end{array}$ & $2,319,297$ & $2,702,373$ & $2,785,008$ & $3,211,096$ & $3,159,851$ & $3,019,520$ & $3,562,25$ \\
7 \\
\hline $\begin{array}{c}\text { Percent of } \\
\text { total }\end{array}$ & 20.8 & 23.5 & 23.9 & 27.2 & 27.3 & 26.5 & 28.6 \\
\hline
\end{tabular}

\begin{tabular}{|c|c|c|c|c|c|c|c|}
\hline Table 3. Branded beef expenditures for ground versus and whole muscle beef, 1998-2004 & & & & & & & \\
\hline & \multicolumn{7}{|c|}{ Percent of total beef expenditures } \\
\hline Ground beef & 19.4 & 22.8 & 22.9 & 25.8 & 24.3 & 27.3 & 32.9 \\
\hline $\begin{array}{c}\text { Whole muscle } \\
\text { beef }\end{array}$ & 21.6 & 32.2 & 24.2 & 27.6 & 28.8 & 25.6 & 25.8 \\
\hline
\end{tabular}

\section{The Modeling Framework}

To shed light on the characteristics of those more likely to purchase branded beef products, analysis of past purchasing habits of consumers using the AC Nielsen panel data for 2004, which includes 7,516 observation households with each observation representing one household. The probability of buying branded fresh beef is specified as a standard logistic model:

$\operatorname{Pr}($ Brand $=1 \mid X)=f(X \beta)=\left\{1+\exp \left[-\alpha-\sum_{k=1}^{t} \beta_{k} \chi_{\mathrm{hk}}\right]\right\}^{-1}$

where "Brand" is the binary brand representation, $\beta$ is the vector of unobserved regression parameters, and $\mathrm{X}$ is a vector of household characteristics expected to have an effect on the probability of buying a branded fresh beef product, including income range, household age distribution, race composition, age range, geographic location (Table 4). The odds of "success" for the $\mathrm{h}^{\text {th }}$ subpopulation group is:

$\theta_{\mathrm{h}} /\left(1-\theta_{\mathrm{h}}\right)=\exp \left\{\alpha+\sum_{\mathrm{k}=1}^{1} \beta_{\mathrm{k}} \chi_{\mathrm{hk}}\right\}$

where $\theta_{\mathrm{h}}$ is the probability of buying branded beef for the $\mathrm{h}^{\text {th }}$ subpopulation group. Taking logs on both sides yields the linear model for the logit:

$\log \left\{\theta_{\mathrm{h}} /\left(1-\theta_{\mathrm{h}}\right)\right\}=\alpha+\sum_{\mathrm{k}=1}^{1} \beta_{\mathrm{k}} \chi_{\mathrm{hk}}$ 


\begin{tabular}{|c|c|c|}
\hline Variables & Mean & Definition \\
\hline \multicolumn{3}{|l|}{ Race } \\
\hline White & .79 & 1 if household identified as white; 0 otherwise \\
\hline Hispanic & .10 & 1 if household identified as Hispanic; 0 otherwise \\
\hline College $^{1}$ & .26 & $\begin{array}{l}1 \text { if the age of the female head of household had } 4 \text { or more years of college; } 0 \\
\text { otherwise. }\end{array}$ \\
\hline Married & .53 & 1 if household couple identified as married; 0 otherwise \\
\hline \multicolumn{3}{|r|}{ 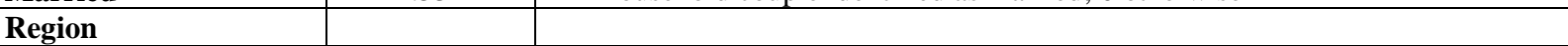 } \\
\hline Central & .23 & 1 if household resides in the Central U.S.; 0 otherwise \\
\hline South & .37 & 1 if household resides in the South; 0 otherwise \\
\hline West & .21 & 1 if household resides in the West; 0 otherwise \\
\hline Household size & 2.61 & Number of members living in the household \\
\hline \multicolumn{3}{|l|}{ Age-female head $^{1}$} \\
\hline $\mathrm{AGEb}$ & .25 & 1 if the age of the female head of household is 40 to 49 years; 0 otherwise. \\
\hline AGEc & .31 & 1 if the age of the female head of household is 50 to 64 years; 0 otherwise. \\
\hline AGEd & .19 & 1 if the age of the female head of household is 65 years or older; 0 otherwise. \\
\hline \multicolumn{3}{|l|}{ Annual income } \\
\hline Midincome & $47,375.23$ & $\begin{array}{l}\text { Midpoint of income range earned by household for income ranges specified by } \\
\text { AC Nielsen (\$). }\end{array}$ \\
\hline
\end{tabular}

\section{BRANDED BEEF EXPENDITURE EFFECTS OF DEMOGRAPHICS}

Variable coefficients estimated using the logit specification are presented in Table 5. Results indicate the statistical importance of each variable. Coefficients associated with "Central," "West," "household size", "AGEc" and "AGEd" are significant at the 5 percent level, while "hispanic," "college," "married" and "South" were significant at the 10 percent level. Three of the 12 variable coefficients were statistically insignificant.

These coefficients have little direct meaning, but are used to calculate the probabilities associated with purchasing branded beef. Figure 1 shows the estimated change in probability of purchasing branded beef associated with those variables that are statistically significant at the 10 percent level or less. Ranked by order of importance, households located in the West are 79 percent more likely to purchase branded beef compared to those in the East. Those with a female head of household age 65 or greater are 41 percent more likely to purchase branded beef than those less than 40 years of age, while those with a female head of household 50 to 64 are 25 percent more likely. This is consistent with previous studies that found the baby boom population (i.e., those 42-60 years) to be more likely to buy branded products compared to younger shoppers (American Institute of Food Distribution, Inc., 2006).

An increase in household size is also estimated to increase the likelihood of purchasing branded beef. A one-member increase in household size is estimated to increase the probability of purchasing branded beef by 11 percent. The Central and Southern regions of the Nation were more likely to purchase branded beef compared to the East, as were households identified as married. Households identified as Hispanic were less likely to purchase branded beef, as were households that had four years of college. 


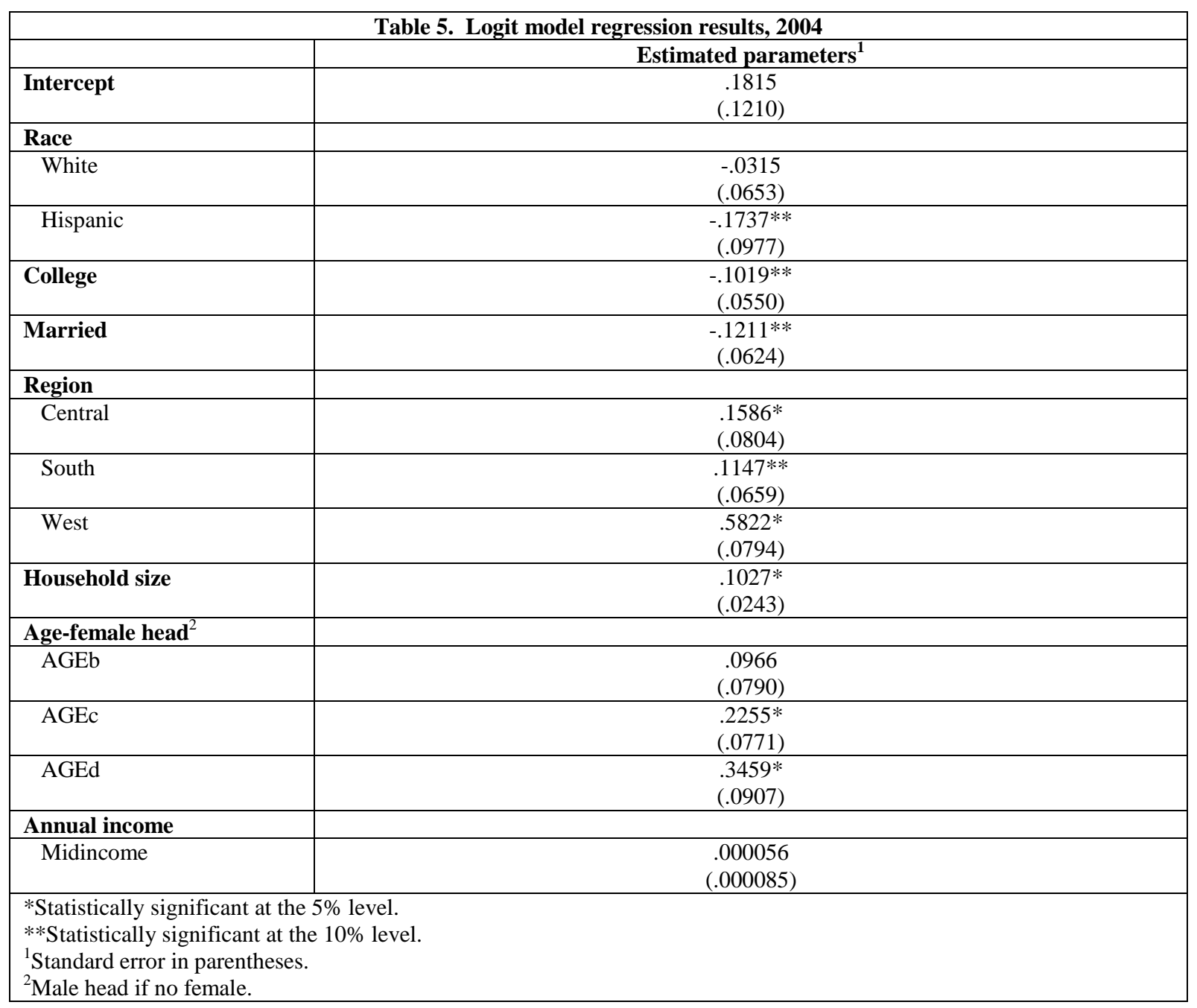




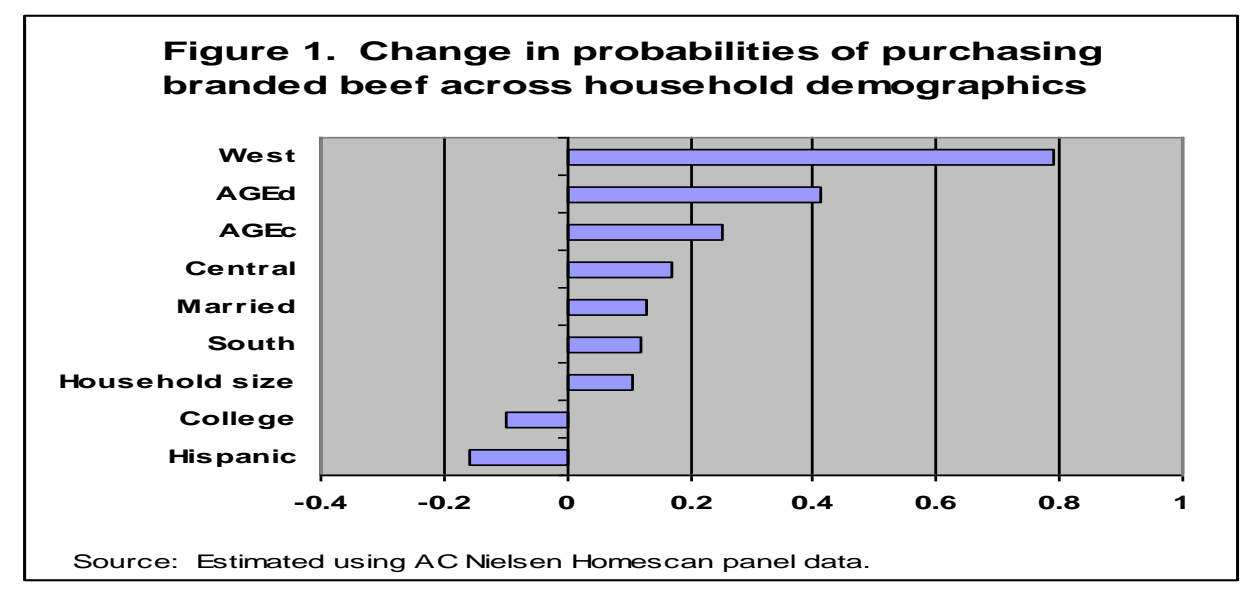

\section{CONCLUSIONS}

Preliminary results from our analysis suggest that households in the West are most likely to purchase branded fresh beef, while those in the East are least likely. Those households with a female head of household that is 50 years of age or older are most likely to purchase branded beef, especially those 65 years or older. An increase in household size also increases the likelihood of purchasing branded beef.

By analyzing demographic factors related to purchases of branded beef products, emerging and future demand can be identified. Blisard, Variyam, and Cromartie (2003) project future population changes to 2020. The proportion of the U.S. population over age 45 is expected to increase, while the percentage under age 45 is expected to decrease. The West is expected to increase in population, while the Northeast is expected to lose population. Assuming that households acquire the purchasing patterns of those already in subpopulation groups, these projections bode well for expenditures on branded beef. For example, a household that moves from the East to the West is expected to acquire the expenditure patterns of those already in the West; namely, a greater likelihood of purchasing branded beef.

These results suggest that branded beef alliances may provide an opportunity to enter programs that satisfy the growing demand for branded beef in a relatively cost-efficient manner, and increase returns to participants. Particularly, this study helps identify specific target market groups for beef producers. This, in turn, may have farreaching implications for how the beef industry operates.

Our analysis will be extended in several ways. First, branded beef categories will be examined to attempt to better match branded beef purchases in the AC Nielsen data with our definition of branded beef purchases. For example, the "CTL brand" classification may contain some generic branded products, which should be excluded from our analysis. Second, other explanatory variables will be added. For instance, Ward and Ferrara (2005) found that increases in price raises the likelihood of buying branded beef and the probability of buying by brand is also higher for supercenters and warehouses. Additionally, analysis of individual purchases can be analyzed instead of aggregate households. Another segmentation of the data may be to separate the purchases of "middle meat cuts" or described sometimes as steak cuts such as ribeye and t-bone products and define their demand characteristics. The same approach could also be used in the ground beef products. Finally, we will increase the sample size by running the model using data from 1998 to 2004. Using panel data from 1992 to 2000, Ward and Ferrara (2005) found statistically significant household preference changes for branded beef over time. 


\section{REFERENCES}

1. American Institute of Food Distribution, Inc. Baby Boomers, A $\$ 43$ Billion Retail Opportunity, The Food Institute Report. August 28, 2006. Fair lawn, NJ.

2. Blisard, N., J.N. Variyam, and J. Cromartie. Food Expenditures by U.S. Households: Looking Ahead to 2020, AER-821, U.S. Department of Agriculture, Economic Research Service, Februrary 2003.

3. Business Wire. Latest IRI Baby Boomers Report Uncovers $\$ 43$ Billion Growth, Press release, August 22, 2006.

4. Harris, J.M. and N. Blisard. Characteristics of the Nielsen Homescan Data. U.S. Department of Agriculture, Economic Research Service.

5. Loureiro, M.L., and W.J. Umberger. A Choice Experiment Model for Beef Attributes: What Consumer Preferences Tell Us. Selected Paper at the American Agricultural Economics Association Annual Meetings, August 2004.

6. $\quad$ Lusk, J., Branded Beef: Is it What's for Dinner? Choices, Spring 2001.

7. Lusk J.L., J.A. Fox, T.C. Schroeder, J. Mintert, and Koohmaraie M. In-Store Valuation of Steak Tenderness. American Journal of Agricultural Economics, 83(2001): 539-550.

8. Martinez, S.W. The U.S. Food Marketing System: Recent Developments, 1997-2006. U.S. Department of Agriculture, Economic Research Service, February 2007.

9. Ward, R.W., and O. Ferrara. Measuring Brand Preferences Among U.S. Meat Consumers with Probit Models. Selected Paper prepared for presentation at the American Agricultural Economics Association Annual Meetings, Providence, Rhode Island, July 24-27, 2005.

10. Washington State Beef Commission. Industry Information: Branded Beef, accessed December 29, 2006 at: http://www.wabeef.org/AboutUs/BrandedBeef.aspx /. 